\title{
Research on Campus Culture Construction of Primary and Secondary Schools Affiliated to China University of Geosciences (Wuhan)
}

\author{
$\mathrm{He} \mathrm{Yi}^{1, \mathrm{a}}$ \\ ${ }^{1}$ China University of Geosciences(Wuhan), Wuhan, Hubei, China \\ 13870913195@163.com
}

\begin{abstract}
The affiliated school of China University of Geosciences (Wuhan) was originally founded to solve the education problem of the children of the faculty and staff of the University of Geosciences. It integrates the preschool education department, primary school department and middle school department. After years of development, it has formed its own characteristics. Education The school has achieved great results. The school has always attached great importance to the construction of campus culture, and has formed a campus culture construction concept centered on the school motto "Enlighten the feelings, advocating truth and advocating beauty". This article summarizes the theoretical principles, characteristics, and cultural construction dimensions of campus culture construction in primary and secondary schools by collating and reading relevant literature on campus culture construction in primary and secondary schools, combined with practical work experience. Based on these theories, combining in-depth interviews and survey questionnaires to study China The campus culture construction of the primary and secondary school affiliated to the University of Geosciences (Wuhan), and finally summarize the experience in the construction of the primary and secondary school campus culture.
\end{abstract}

Keywords: Primary and secondary school campus culture, Affiliated school, Behavior, System, Culture.

\section{INTRODUCTION}

Culture play the role of integration, guidance, maintenance of order and continuity, and campus culture is the reflection of the spirit of the times in the school, and is a kind of group consciousness formed in the long-term development of the direction and guiding ideology of socialist schools【1】.A healthy campus culture can cultivate students' sentiments, enlighten students' minds, promote students' all-round development, improve the quality of school education and teaching, and help the construction of teachers, which is of great significance in today's school education【2】. The affiliated school of China University of Geosciences (Wuhan) was established in June 1977. It is a second-level unit directly under China University of Geosciences (Wuhan). Modern basic education school. The affiliated school has always paid attention to the construction of campus culture, is committed to exploring new ideas and new ways of school development, and strives to build cultural characteristics that can promote the sustainable development of the school 【3】.The school has formed a campus culture construction concept of "Enlightenment, Enlightenment, Advocating Truth and Beauty", continuously promotes the development of the school's connotation, and constantly presents a pleasant, intelligent, and beautiful humanistic environment. However, the construction of campus culture of affiliated schools still needs to continue to work hard to continuously explore campus culture with its own characteristics.

\section{CHARACTERISTICS OF CAMPUS CULTURE}

\subsection{Culture and behavior are inseparable}

Culture has the function of invisibility and permeability, and can guide people's behavior through the active function of human consciousness【4】.The construction of behavioral culture is the ultimate goal of cultural construction, and it is the conscious culture formed by teachers and students. An important result of 
cultural education is the change of cultural behavior. To realize cultural education, we must start from changing people's cultural behaviors. Cultural behavior is one of the important behaviors in human behavior. Cultural behavior will affect other behaviors and affect people's choices of other behaviors 【 $5 】$. Therefore, the breakthrough of cultural education in elementary and middle schools in the new era is to encourage teachers and students to change their cultural behaviors, so that teachers and students can internalize and form their own cultural behaviors under the influence and infection of culture.

\subsection{A good system is the basic guarantee}

Having a good institutional framework can promote the long-term operation of campus culture construction, which is conducive to maintaining the normal order of the school. The school formulates scientific and reasonable rules and regulations that are in line with the school's actual conditions to promote the healthy development of students, as well as the professional development of teachers and improve the quality of school education and teaching 【6】.Good campus rules and regulations can become a code of conduct that all teachers and students consciously abide by, and jointly maintain, standardize their words and deeds, stimulate vitality, and fully mobilize the enthusiasm and creativity of teachers and students to work together to build a good campus culture and run a good school 【7】.

\section{EVALUATION ON THE CAMPUS CULTURE CONSTRUCTION OF PRIMARY AND SECONDARY SCHOOLS AFFILIATED TO CHINA UNIVERSITY OF GEOSCIENCES (WUHAN)}

\subsection{Research and design}

In order to better study the campus culture construction of the primary and secondary schools affiliated to the University of Geosciences, the author conducted a field survey on the schools affiliated to the University of Geosciences. The survey adopts the interview method and questionnaire survey method. Based on the existing campus culture construction of the affiliated school of the University of Geosciences, relevant management personnel and teachers are selected for in-depth interviews, and then based on the interview feedback, the key points of the interview are selected for school teachers and students' parents to issue questionnaires for investigation.

\subsection{Interview and questionnaire survey}

According to the survey design, the author selected four relevant leaders and frontline teachers from the affiliated school to conduct in-depth interviews. I have a preliminary understanding of the basic situation and some problems of the campus construction of the affiliated school, and at the same time I have a general grasp of the relevant participation and activity feedback of the students and their parents.

The teacher version questionnaire has 75 answers and 72 valid questionnaires. The proportion of teachers is evenly distributed. The number of students' parents' version is 961, and the valid questionnaire is 934. Most of the parents have a bachelor's degree or above, accounting for $54.36 \%$, which is in line with the orientation of a university affiliated school. Most of the parents of students are school faculty and staff. Analyzing the results of the questionnaire return, the reliability and validity of the questionnaire are all high (see Figure 1, Figure 2, Figure 3, Figure 4), indicating that the questionnaire design is reasonable. Respondents are generally satisfied with the campus culture construction of primary and secondary schools in affiliated schools.

\subsection{Interview and questionnaire results}

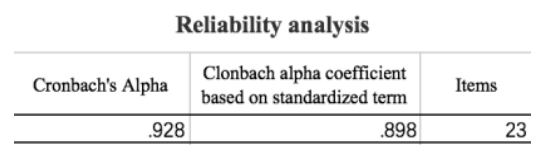

Figure 1: Reliability analysis of teacher questionnaires

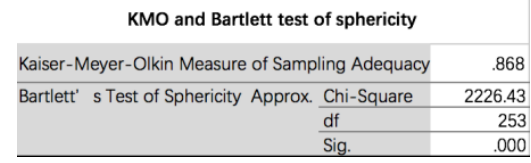

Figure 2: Validity analysis of teacher questionnaires

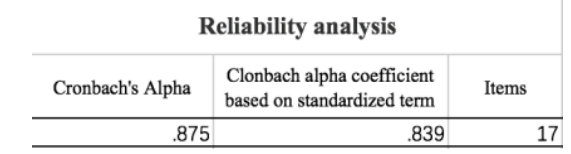

Figure 3: Reliability analysis of the parent questionnaire

KMO and Bartlett test of sphericity

\begin{tabular}{|lrr|}
\hline Kaiser-Meyer-Olkin Measure of Sampling Adequacy & .883 \\
\hline Bartlett' & s Test of Sphericity Approx. Chi-Square & 24634.717 \\
\cline { 2 - 3 } & df & 136 \\
\cline { 2 - 3 } & Sig. & .000 \\
\hline
\end{tabular}

Figure 4: Validity analysis of the parent questionnaire

\subsubsection{Campus environment}

The affiliated school has a beautiful campus environment, with relevant slogans posted on the playground, the corridors of the teaching building, and each class. The class building has a book corner and themed blackboard newspaper. And content such as slogans and bulletins will be updated regularly to fit 
current events. Most of the interviewees are more satisfied with the construction of campus cultural environment-related facilities, and are more certain of the role these infrastructures play in the construction of campus culture.

\subsubsection{System building}

The school campus culture-related system construction is relatively complete, and the weekly meeting, morning meeting, and study meeting will be used to emphasize the focus of this week's work and decide the theme of the weekly class meeting. The theme of school-related large-scale cultural activities also has its basis for selection. At the same time, each class can carry out related activities according to the specific situation of the class. The school will also set different moral education goals for different grades, carry out daily sentimental classrooms, and promote quality education at the same time, allowing students to choose different interest classes every semester to promote students' diversified development.

The school has a sound supervision and feedback mechanism. The school requires that the construction of campus culture be integrated into the daily work of the class. Classes will be evaluated and assessed every semester. At the same time, the assessment results will be linked to the teachers' monthly performance salary and annual selection. At the same time, school teachers and parents also have corresponding communication mechanisms. Parents participate more daily and have a higher willingness to participate. The school has an official account to keep up with the campus dynamics, and even some classes have launched a class official account to interact with the parents of students.

\subsubsection{Behavior}

In order to promote the construction of campus culture in primary and secondary schools, the school has carried out a number of activities. The school will display student quality education, organize science, culture and art festivals and other activities. Every year, it will hold celebrations on Teacher's Day. Large-scale holidays will also carry out supporting activities. In addition, the school will also carry out cultural activities online, National security theme activities, etc. And the school will uniformly determine a class meeting theme every week, and each class needs to carry out the theme class to educate students according to the school's requirements. Most of the interviewees have a positive attitude towards the development of these activities, believing that they can play a certain role in promoting the growth and development of students, and most parents are more supportive of their children to participate in these activities, and their own willingness and degree of participation are also relatively high.

\section{IMPROVEMENT MEASURES}

\subsection{Further strengthen the construction of school hardware facilities}

According to field surveys and questionnaire surveys, the affiliated school's campus culture-related slogans and other facilities are relatively complete, but they still lack relevant supporting hardware facilities such as activity rooms. According to some teachers, the construction of the library corner of campus classes is also a mere formality, and it does not play a good role. To better promote the construction of campus culture, it is necessary to further strengthen the construction of school hardware facilities 【 8】.The conditions for running a school are the basis for the construction of campus material culture. Only by improving the relevant hardware facilities can students better learn, exercise and improve themselves.

\subsection{Increase the frequency of communication between teachers and students' parents}

Although according to the results of the questionnaire survey, most parents believe that they communicate with their teachers more frequently, some parents still expressed the hope that the exchanges can be closer in the future, mainly in the form of parent conferences. The parent conference is not only a platform for parents to take the initiative to communicate with teachers, but also an opportunity for parents to have an in-depth understanding of school teaching and compare their children horizontally and vertically 【9】.At the same time, parents can also communicate with each other. It is recommended to increase the number of parent meetings held in the future to increase the frequency of communication between teachers and parents. In addition to the class teacher, communication between other teachers in the class and parents should also be appropriately increased, so that parents can understand the specific situation of their children's learning.

\subsection{Pay attention to the guidance of student behavior and prohibit violent behavior}

Although most of the students' behaviors are well-regulated, it is not ruled out that some students have irregular behaviors. Among them, hygienic and polite behaviors can be corrected by teachers and the school's rules and regulations. Violent behaviors such as provoking troubles, fighting and fighting need to arouse our extra attention. Some male classmates like to 
jokingly engage in minor physical collisions with classmates, but they tend to evolve into fights in the end. Regarding this kind of behavior, whether subjectively or deliberately or joking, it should be guided, ordered to prohibit, and prevent it from becoming more violent, and even evolve into campus bullying and campus violence. Students who have conflicts should seek normal solutions instead of any form of violence. Some parents report that their children have been bullied and violent at school, which is not only not conducive to the construction of a harmonious campus culture, but also easily causes psychological effects and misunderstandings on these young children.

\section{CONCLUSION}

\subsection{Humanized design, teaching students according to their talents}

A very important point in building a school culture in primary and secondary schools is to put people first and teach at different levels. At the same time, it has designed different management methods for different subjects. All school activities and weekly main class meetings are conducted uniformly at the school level, and many systems have specific standards and norms. This is conducive to the assessment and management of the school, but to a certain extent it is also not conducive to exerting the subjective initiative of frontline teachers. In this regard, the school gives each class teacher the autonomy to decide on their own class activities. The teacher in charge of each class can choose the activity subject and design the activity form according to the specific needs of their class. This is conducive to better meet the individual needs of students and teach students in accordance with their talents. At the same time, the school will regularly monitor and evaluate the development and effectiveness of the activities to ensure the quality of the activities.

\subsection{Make full use of the superior resources of universities}

The affiliated school has always been working hard to cultivate morality and cultivate people. In order to achieve the goal of "sentiment and wisdom" and cultivate students' sentiment, the school vigorously develops quality education. Culture and behavior are inseparable, and campus culture needs to be cultivated through specific behaviors. Therefore, the school requires each student to have one or two specialties. The affiliated school has opened more than 40 free interest classes. Students in grades one to six can choose courses online every semester to cultivate different hobbies. Interest classes are held every Thursday and Friday afternoon. By adding extra-curricular interest classes, the school has extended the teaching time to a certain extent. After this adjustment, the school's end-of-school time is also in line with the parents' off-duty time, and to a certain extent, the parents' burden is reduced. burden. And some of the students who teach these extracurricular courses are students from China University of Geosciences (Wuhan). Relying on the hand-in-hand and co-progress support team, the school recruits college students for work-study programs every semester and opens interest classes in affiliated schools, which also saves the school's funds to a certain extent. In addition, relying on universities, affiliated schools can also invite university professors to give lectures to students.

\subsection{Integrate the construction of campus culture into all aspects of campus management}

The construction of campus culture needs to be integrated into all aspects of campus management. Campus culture has a group characteristic, and students are easily affected by group behaviors. The integration of campus culture construction into all aspects of campus management is conducive to forming a strong atmosphere on campus and influencing students unconsciously. At the same time, this is also conducive to regulating the various behaviors of school personnel. Culture has the characteristics of invisibility and permeability. Teachers and students will internalize and form their own cultural behaviors under the influence and infection of culture. The standard of behavior is also conducive to Enhance cultural influence. The affiliated school integrates the construction of campus culture into various management tasks, whether it is daily sanitation inspections, the development of morning meetings and seminars, the assessment and evaluation of teachers, students and classes, or the development of various unique activities of the school. Implementing the requirements of campus culture construction.

\section{REFERENCES}

[1] Li Yue. Research on the function of the school motto of primary and middle schools in the construction of campus culture [D]. Huazhong University of Science and Technology. 2019(04)

[2] Wang Yun, Fan Jiahong. Study on Critical Thinking of Learners in Online Discussion [J]. China Education Information. 2021(08): 8-12

[3] Lu Huifen. The Four Organic Combinations of Red Culture and Moral Education in Primary and Secondary Schools[J].Caizhi.2014(04):215-216

[4] Ren Caijin, Ma Zhiying, Chen Lihan. The actual dilemma of Chinese excellent traditional culture entering the campus and its solution $[\mathrm{J}]$. Modern Communication. 2021(04): 28-30 
[5] Zhang Zhigang. Thoughts on promoting the cultivation and practice of socialist core values and integrating it into the construction of campus culture-Taking elementary and middle schools in Fujian Province as an example [J]. Journal of Fujian Education Institute. 2014(01): 40-43+128

[6] Dayu County Political Consultative Conference Mei Zhuoyun. "Three Keys" to enhance the level of campus culture construction [N]. Guanghua Times. 2018

[7] Wang Xiaodi. The connotation, predicament and path of cultural education in elementary and middle schools in the new era $[\mathrm{J}]$. Teacher Education Forum. 2020(12): 63-66

[8] Wei Wei, Ma Guidan, Li Hongyu, Chen Lijie, Zhang Hong, Yang Juan. Research on the Cultivation of Students' Moral Education Under the New Curriculum Reform [C].216-221

[9] Yang Dan. Analysis of the importance and countermeasures of the construction of a harmonious campus culture in primary and secondary schools in the new era $[\mathrm{J}]$. Popular Literature and Art. 2020(06): 190-191 